Retos, 10(20), 2020

\title{
La adaptación versus la estandarización visto desde el paradigma de marketing esencial
}

\section{Adaptation versus standardization seen from the essential marketing paradigm}

Dr. José Antonio París es profesor de Marketing Internacional e investigador de la UNLP (Argentina) (marketing.jose.paris@gmail.com) (https://orcid.org/0000-0002-4561-1441)

\begin{abstract}
Resumen
La literatura actual del marketing internacional acerca de la controversia de aplicar una política de adaptación o de estandarización de producto a la hora de lanzarlos a los mercados externos. Ahora, toda ella se refiere a la consecuencia de utilizar una u otra, pero ningún autor se ha detallado a identificar cuáles son las causas esenciales que nos permitan tomar tan importante decisión del marketing internacional. Este documento analiza esta problemática desde la óptica del paradigma del marketing esencial y trabaja básicamente sobre el análisis del impacto de los cuatro aspectos esenciales que son los activadores del consumo, y de qué manera estos impactan sobre esta problemática en cuestión. Para abordar esta problemática se ha ingresado de manera decidida tanto en la mente del consumidor, como en la mente del mercado. Y se presentan en este documento no solo los cuatro activadores o motivadores de compra, sino también cuáles son sus motores impulsores, además de lo que los mismos representan desde la neurociencia.

Luego para completar dicho documento se argumenta apologéticamente, como esta conceptualización teórica impacta sobre las decisiones de marketing internacional, por lo menos, a la hora de decidir si el producto o servicio en cuestión se puede estandarizar o habrá que realizar algún tipo de adaptación al mercado de destino internacional. Finalmente, se propone un modelo de valor en forma de patronage del consumo, y del cual se puede apreciar toda la problemática esencial.
\end{abstract}

\begin{abstract}
There is a lot of international marketing literature about the controversy of applying a product adaptation or standardization policy when launching them to external markets. Now, all of it refers to the consequence of using one or the other, but nothing is said about how the essential causes intervene in this important decision of international marketing. This document analyzes this problem from the perspective of the essential marketing paradigm and basically works on the analysis of the impact of the four essential aspects that are the activators of consumption, and how they impact on this problem in question. To address this problem, it has been decidedly entered both in the mind of the consumer and in the mind of the market. And this document presents not only the four activators or purchase motivators, but also what are their driving engines, in addition to what they represent from neuroscience.

Then to complete this document it is argued apologetically, as this theoretical conceptualization impacts international marketing decisions, at least, when deciding whether the product or service in question can be standardized or some type of market adaptation will have to be made of international destination. Finally, a value model is proposed in the form of "pattern" of consumption, and from which you can see all the essential problems.
\end{abstract}

\section{Palabras clave I keywords}

Activadores, adaptación, arquetipo, código, estandarización, percepción, políticas, significado. Activators, adaptation, archetype, code, meaning, standardization, perception, policies.

Cómo citar: París, J.A. (2020). La adaptación versus la estandarización visto desde el paradigma de marketing esencial. Retos Revista de Ciencias de la Administración y Economía, 10(20), pp. 195-217. https://doi.org/10.17163/ret.n20.2020.01 


\section{Introducción}

\subsection{La dicotomía adaptación versus estandarización}

Cuando el sociólogo canadiense Marshall McLuhan definiera el concepto de 'aldea global' en 1962, se inició la discusión entre quienes querían impulsar sus negocios internacionales desde la adaptación de sus planes de marketing y quienes veían en la estandarización el mejor camino hacia los negocios más rentables. Si bien McLuhan (1989) utiliza este nuevo neologismo de aldea global para describir las infinitas posibilidades de interconexión humana a escala global que se estaban posibilitando por los nuevos accesos a los medios electrónicos de comunicación, también dicho autor no anticipa que con ello terminó por abrir un debate profundo del marketing internacional que llega incluso hasta nuestros días. Luego, para reafirmar todas estas ideas en 1989 junto con B.R. Powers escriben The global village. También en la década de los sesenta el autor Erik Elinder (1965) predecía que había millones de europeos que en gran medida vivían en condiciones similares, aunque habitaran en distintas naciones, si bien Elinder no llegó a hablar de globalización del consumo, y tampoco de estandarización, sí puso énfasis en la uniformidad y sugirió una comunicación internacional.

Fue R. Buzzell (1968) quien definiera el concepto de estandarización al afirmar que se trataba de una oferta de idénticas líneas de producto, a precios similares a través de los mismos tipos de canales de distribución y con idénticos planes de comunicación en diferentes naciones y países del mundo. Pero, como lo escribiéramos en nuestro libro Marketing internacional desde la óptica latinoamericana (París, 2015a), fue Levitt (1983) quien finalmente planteó la gran controversia en 1983 con su artículo sobre la globalización de los mercados. Levitt afirmaba que los mercadólogos del mundo se confrontaban en una 'aldea global homogénea', argumentaba que la misma estaba gestando el surgimiento de un único consumidor global. Por lo que él recomendaba a las empresas que diseñaran y produjeran productos y servicios para este nuevo consumidor. Es decir, generar productos y servicios altamente estandarizados, de alta calidad y que los comercializaran en todo el mundo utilizando políticas de productos, precios, distribución y comunicación globales. Y esta idea fue muy bien recibida por las empresas líderes internacionales de ese momento, las primeras en tomarlo fueron las japonesas: Toyota ${ }^{\circledR}$, Sony ${ }^{\circledR}$, Citizen ${ }^{\circledR}$, Panasonic ${ }^{\circledR}$, Casio ${ }^{\circledR}$, entre otras. Y muchas de ellas lograron resultados sorprendentes, sobre todo aquellas dedicadas a los bienes electrónicos, automotores, digitales y bienes de capital. Esto derivó en un nuevo modelo de organización empresarial internacional: la transnacional. Tipo de empresa internacional que, además de no realizar adaptaciones a las preferencias locales, diseña sus productos de acuerdo a las preferencias de un supuesto consumidor global.

Pero, como es de prever, no todas las organizaciones que abrazaron esta ideología de la estandarización del marketing internacional tuvieron éxito, a decir verdad, en muchos sectores fracasaron, pues se encontraron con enormes obstáculos provocados por las tradiciones regionales, con usos y costumbres muy arraigados, fruto de cosmogonías muy diferentes, y claro está por las distintas culturas de las naciones. Tal como lo plantea el autor norteamericano el politólogo Huntington (1997) en su libro El choque de civilizaciones, quien predijo antes de su deceso ( $\left.{ }^{2} 2008\right)$, que el futuro de los conflictos del mundo se iba a dar entre las distintas civilizaciones que lo componen. En este 
nuevo reordenamiento internacional se anticipa que los nuevos conflictos humanos y entre las distintas naciones no serán del tipo económicos, ni ideológicos, tampoco geopolíticos, sino ante todo culturales. Así, lo vaticina Samuel Huntington, al tiempo que presenta un futuro lleno de conflictos, pero en un ambiente gobernado por unas relaciones internacionales abiertamente contrarias a los intereses occidentales, y este autor acaba reconociendo la necesidad de que occidente obtenga un conocimiento más preciso de las civilizaciones no occidentales, con el fin de lograr un mejor acercamiento a estas culturas para así potenciar su máxima influencia. Incluso no son pocos los autores que llegan a otorgar gran parte del peso de la culpa de la crisis del 2009, al enorme costo asumido por las organizaciones internacionales que buscaron imponer el estilo de vida occidental al resto del mundo a través de la aplicación de la política de estandarización global promovida por Levitt.

Esta controversia del marketing internacional ha derivado en tres escuelas: la impulsora de la adaptación, la promotora de la estandarización y luego surgió una tercera alternativa la que sostiene la posición intermedia:

1. La escuela de la adaptación: aquí se toma la cultura local como parte del 'input' del marketing internacional. Poniendo especial atención en los usos y costumbres de los consumidores del país de destino. El potencial éxito del plan de marketing internacional se basa en el conocimiento de lo local y tanto los productos como los servicios se adaptan a las preferencias de sus consumidores. Quienes defienden este enfoque alegan que las diferencias culturales entre las distintas naciones, las diferentes fases de sus ciclos económicos, las desiguales curvas del ciclo de vida del producto y los muchos estilos de vida de sus ciudadanos son barreras imposibles de sortear, a no ser que sea la organización la que se adapte a las mismas con sus productos o servicios. También son problemáticas las diferencias entre los distintos sistemas políticos y legales, además de las variables estructurales sociales y económicas que suelen no ser similares. Autores como Boddewyn, Soehl y Picard (1986) son firmes defensores de esta escuela.

2. La escuela de la estandarización: esta ideología propugna que el consumidor se está globalizando a una velocidad como nunca antes se ha visto gracias a las TIC (tecnologías informáticas y de la comunicación), lo cual repercute en una acelerada convergencia de los mercados, según los preceptos de Theodore Levitt (su máximo referente). El autor Peebles (1978) reconoce diferencias con respecto a la esfera local, pero tampoco cree que las mismas sean insalvables o determinantes. Luego muchos autores sostuvieron esta ideología, algunos de manera contundente como Bruhn (2004), quien incluso sostiene que se debe buscar implantar el concepto ya exitoso a nivel nacional, en otros mercados similares o incluso distintos, pero sin producir apenas modificaciones del mismo. Otros autores pro-estandarización como Madeira y Silveira (2013) y Postigo (2014) consideran que las born global son empresas internacionales que no siguen las etapas tradicionales de su internacionalización, sino que apuestan desde su inicio al mercado global. 
3. La escuela de la posición intermedia: esta vía reconoce las ventajas de ambos extremos y trata de compatibilizarlos con una propuesta inteligente para cada caso. Esta escuela promueve la moderación como respuesta a los dos extremos, pues se reconocen las diferencias a nivel local, pero también defienden las ventajas de la estandarización, ya que ven con agrado la reducción de costos. Entre otros autores que han abrazado esta postura o vía intermedia se encuentran Papavassiliou y Stathakopoulus (1997), quienes plantean una serie de condicionantes internas y situaciones circunstanciales externas las que modifican las acciones mercadológicas y así optar por la adaptación o estandarización según el caso; o como lo establecen Onkvisit y Shaw (1987) quienes afirman que más que una cantidad de diferencias se trata de una cuestión de grados. Esta postura es criticada por ser ambigua, poco clara, y a veces confusa.

En lo que sí concuerdan todos los enfoques es en cómo lo afirma Sainz de Vicuña (2016), en que la decisión de internacionalizar un negocio obedece al principio básico de contar con empresas con capacidad de proyectarse de manera internacional en el tiempo con rentabilidades que les permitan crecer y expandirse. Aunque, todas estas escuelas se plantean la problemática desde la óptica de sus consecuencias de sus respectivas aplicaciones, pero ninguna de ellas identifica las causas esenciales desde la problemática basal del plan de marketing internacional. Pues bien, en este trabajo nos propondremos realizar el análisis desde sus causas esenciales y para ello recurriremos a nuestro análisis estratégico desde los dos sitios de investigación del mercado: la mente del consumidor y la mente del mercado. Sitios de los que hemos extraído los cuatro aspectos esenciales activadores del consumo, tanto para el marketing doméstico como para el marketing internacional: las percepciones y los significados en la mente del consumidor; y los códigos de comportamiento y los arquetipos en la mente del mercado.

\section{Los dos sitios de los aspectos de base de un plan de marketing internacional}

Ya hemos dicho que, para estudiar el comportamiento del consumidor, debemos introducirnos definitivamente en dos sitios: la mente del consumidor y la mente del mercado. Cuando Philip Kotler (2005) afirmó que el marketing debía introducirse totalmente en la mente del consumidor, en realidad no dejó en claro con qué herramientas desarrollar tan encomiable tarea. Ya que una cosa es decirlo y otra cosa es tratar de realizarlo con las herramientas que ofrece el marketing tradicional en este sentido. Por otro lado, este autor tampoco desarrolla la mente del mercado, a decir verdad, no evalúa su real potencial mercadológico, pues el accionar del 'inconsciente colectivo' no solo condiciona, sino que incluso hace cambiar la decisión de compra del consumidor cuando éste está influenciado por los demás a partir de los códigos de comportamiento y los vínculos que se generan, pero también de las posturas que adoptan cuando se encuentran rodeados por otras personas. Sin dudas, que toda esta problemática llevó al marketing a una profunda crisis en la que aún se encuentra inmerso. Fruto de esa crisis surge 'la segunda miopía del marketing' la que ya hemos denunciado en nuestro libro homónimo, y por la cual se detectan en la actualidad un nivel de fracasos de más de un $85 \%$ de los productos y servicios que se lanzan a los mercados externos o distintos al propio (París, 2012). 
Sin embargo, Kotler (Kotler, 2005) en su libro Los 10 pecados capitales del marketing ha identificado y analizado al menos una decena de importantes fallas del marketing actual, en los que comúnmente incurren las empresas y negocios internacionales. Entre algunas de las razones de dicho fracaso, podemos citar el primer pecado que Kotler (2005, p. 15) destaca: "La empresa no está suficientemente orientada al mercado y dirigida a los consumidores". Sin dudas, que es la primera causa de error, y esto se debe al alto desconocimiento de los motivadores de compra, que ha decir verdad este autor nunca se enfocó de manera integral, sino que a lo sumo analizó de manera muy superficial sin llegar a las causas esenciales del consumo. Esto se debe, por una parte, a que los expertos en marketing no están tomando en cuenta los cambios que ha sufrido el mundo mercadológico en su conjunto, ya que el consumidor y el mercado en su conjunto se han vuelto mucho más complejos e impredecibles, y esto si sucede a nivel doméstico, es mucho más complejo a nivel internacional; $y$, por la otra, al reduccionismo que ha ido sufriendo el marketing en cuanto a modalidad de investigación, el tiempo que se le otorga a dicha investigación mercadológica y por la escasa inversión realizada para la interpretación de la problemática que presenta el mercado de hoy en día que, según nuestra óptica de marketing esencial, es la principal causa, ya que no se visualiza el problema de manera heurística, integral y holística. La gran dificultad que se visualiza es que el problema se ataca desde una sola de las ópticas del marketing, generado por algunos de sus enfoques: digital, de responsabilidad social, verde, móvil, viral, etc. Pero, nunca se lo ataca desde sus distintos ángulos ya que el marketing esencial requiere de la integración de los saberes como ser: axiología, semiología, neurociencia, antropología, sociología, psicología, economía, comunicación y comportamiento del consumidor.

Además, como el mercado está en permanente cambio, se requiere de una constante actualización metodológica, ya que el marketing es esencialmente heurístico, es decir, se descubre y se redescubre cada día, tanto en la mente del consumidor como en la mente del mercado. Hoy nada es estático, y lo que no se mueve o cambia, muere, por el ya reconocido fenómeno neurocientífico de la abruption. Por este último fenómeno se afirma que todo aquello que se deja de estimular en la mente del consumidor y en la mente del mercado, termina por perder significado o incluso desaparecer como concepto en la mente del consumidor y del mercado. Nosotros sostenemos que la mente humana se carga de contenidos a través de la percepción, actuando como una base de significados, los cuales se interrelacionan y son guiados por los códigos, y terminan estandarizándose en forma de arquetipos. El autor y antropólogo brasileño Arduini (2006), se ha preguntado en su libro Antropología, atreverse a recrear la humanidad: ¿qué es el hombre?, y su respuesta fue aún más sorprendente: "el hombre es una mina de significados". Y con esta frase nos invita a buscar las vetas que ofrece el hombre como consumidor. Por lo tanto, lo básico para el marketing debería ser interpretar cual es el agente activador del requerimiento por el producto o servicio.

En los siguientes esquemas gráficos de las Figuras 1 y 2 se aprecia como de la mente del consumidor podemos extraer las percepciones y los significados, mientras que de la mente del mercado podemos obtener los códigos simbólicos/culturales y los arquetipos. Aunque, vale decirlo el marketing tradicional no nos prepara para realizar estas tareas de investigación, y como estos aspectos rigen en buena parte las leyes del 
mercado y el comportamiento del consumidor la situación se torna muy dificultosa. Ya que estos cuatro aspectos son las bases del plan de marketing tanto doméstico como internacional, y no comprenderlos con claridad implica caer en 'la segunda miopía del marketing'.

Figura 1. El origen de la percepción y del significado del producto

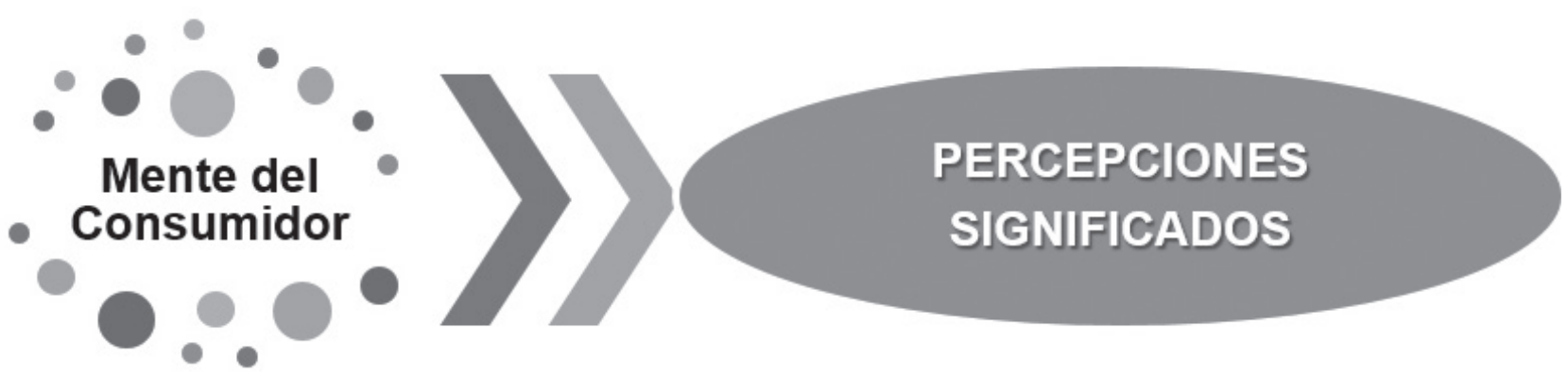

Figura 2. El origen del código simbólico / cultural y los arquetipos
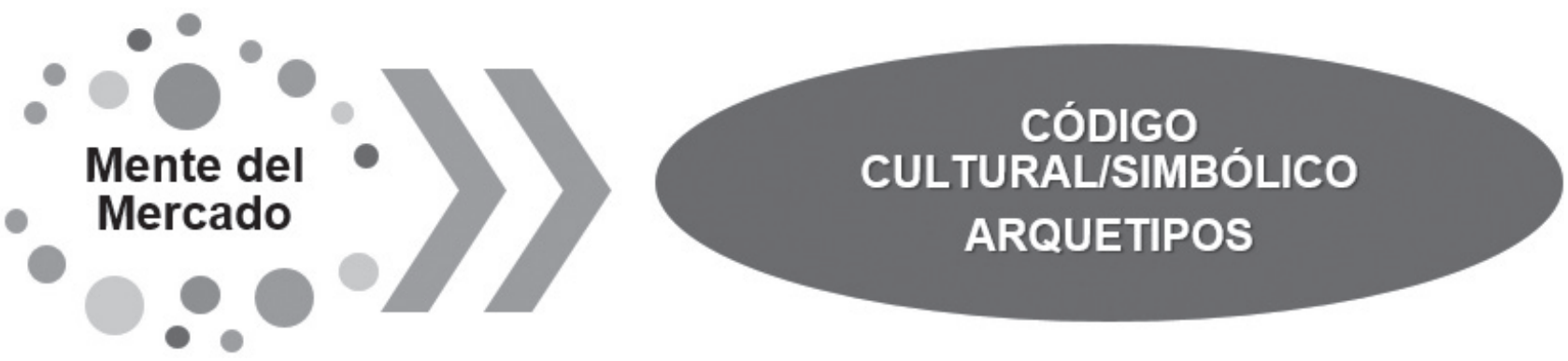

\section{El cuadrado semiótico de Greimas en los cuatro aspectos esenciales del marketing}

En buena parte de nuestros libros hemos aplicado el cuadrado semiótico de Greimas (1983) y quizás la más significativa de nuestras aplicaciones sea la que nos permite interrelacionar los cuatro aspectos esenciales del marketing, que son los movilizadores naturales del consumo. Para realizar esta aplicación partimos de cuatro proyectos de investigación dirigidos por este autor en la Facultad de Ciencias Económicas de la Universidad Nacional de La Plata, en los que hemos analizado dichos aspectos basales del marketing esencial y de los cuales los dos elementos que hemos supuestos como muy diferentes son los Significados y los Arquetipos, los que a su vez cuentan con sus respectivos opuestos (París et al., 2016). Ver Figura 3.

Ahora bien, cuando hablamos de significados nos referimos a las representaciones psíquicas de los productos y servicios en la mente del consumidor. Desde el punto de vista neurocientífico un significado es un camino neuronal estable, que en general se aloja en las memorias con que dispone el cerebro límbico. En este punto tal como lo afirman los biólogos Audesirk et al. (2003), prácticamente todo el conocimiento del hombre está definido como caminos neuronales. Al estar en la mente del ser humano, 
los individuos pueden recurrir a ellos en cualquier momento, por esta razón los significados son los accionadores de los deseos, ya que estos son recuperados y levantados desde las memorias del inconsciente. Por lo tanto, los significados son los responsables de los gustos personales, y mediante los cuáles las personas generan cierto interés y valorización por determinadas cosas o ideas.

En cuanto las figuraciones arquetípicas (o arquetipos) son parte del inconsciente colectivo de las diferentes sociedades y culturas, y se deben interpretar en la mente del mercado. Son una especie de cajas preconcebidas las que se pueden estar cargadas con energía emocional positiva o negativa, dando como resultado los arquetipos del lado claro o del lado oscuro respectivamente. Por ejemplo, si cargamos a la caja de vínculos con el otro con energía emocional positiva, como ser: sinceridad, lealtad, confianza, confiabilidad, ecuanimidad, alegría, simpatía y apego; la figura arquetípica que se obtendrá será la de 'amigo'. Ahora, si cargamos la misma caja con energía emocional negativa, como ser con: odio, envidia, rencor, celos, asco, mezquindad, repudio, venganza, intriga y resentimiento; la figura arquetípica que se obtiene es la de 'enemigo'. Ahora, desde el punto de vista neuronal los podemos visualizar como engramas del cerebro reptílico. Estos engramas según Montserrat (2001) profesor de la Universidad Autónoma de Madrid son estructuras de interconexión neuronal estables (generalmente alojadas en el cerebro primitivo de reptil). Estas complejas redes neuronales, cuando actúan mediando o no un correlato psíquico, estimulan la activación de respuestas automáticas en las cuáles cuando se activan posturas de las que también es muy difícil salir. Por eso se habla de posturas inamovibles. Siendo entonces los arquetipos los responsables principales de las reacciones sociales primitivas, cuyo origen se encuentra en lo profundo del inconsciente colectivo de las culturas y sus sociedades. Algunos ejemplos de arquetipos opuestos son los siguientes: héroe-cobarde, estadista-tirano, princesa-bruja, etc.

Siguiendo el cuadrado de Greimas, ahora presentamos los opuestos de ambos conceptos anteriores: las percepciones frente a los arquetipos, y a los códigos de comportamiento en oposición de los significados.

Sabemos que las percepciones dan en el límite entre los sistemas de referencias externos e internos. Según Mariano Sigman (2015) en las percepciones intervienen tanto los sistemas aferentes como los sistemas eferentes neuronales, tal como lo expresa en su libro La vida secreta de la mente. En sí, el fenómeno a partir de la capacidad humana de captar las señales físicas del ambiente que toman forma de estímulos a nivel sensorial. Y esto ocurre a partir de los cinco sentidos. Cada uno de ellos cuenta con células especializadas que captan los estímulos físicos externos para convertirlos en señales eléctricas, como ser: cilios olfativos, papilas gustativas, bastones visuales, etc., los que generan los impulsos eléctricos y ese impulso genera sensaciones que van a propiciar las asociaciones instantáneas de neuronas a través del proceso de la sinapsis los que luego son procesados en las áreas cerebrales correspondientes (por ejemplo, las señales de imagen en el lóbulo occipital). A esta asociación instantánea neuronal la denominamos percepción. Por lo tanto, la percepción se apoya en las necesidades básicas y derivadas del individuo que requiere para ser activada, y claro, éstas se tienen que interpretar en la mente del consumidor. Al ser particulares de cada individuo, son personales y dependerán de qué requiera cada persona, aunque debemos anticipar que las necesidades humanas son en general similares. 
Finalmente, los códigos de comportamiento (ya sean culturales o simbólicos) son desde el punto de vista neurocientífico verdaderas 'redes neuronales' y son conformados por el inconsciente colectivo para generar relaciones vinculares con los otros individuos que responden a una determinada sociedad y cultura. Por lo tanto, su origen está en la acción colectiva de las personas, las que al buscar vivir en sociedades libres de conflictos y en armonía crean códigos como redes de significados interrelacionados entre sí. Por este motivo los códigos se apoyan en las convenciones sociales generadas a lo largo del tiempo y a partir de la interrelación de varios significados ya conocidos por los individuos integrantes de dicha sociedad. Estas redes neuronales actúan como una especie de filtros 'pasa o no pasa' de la conducta humana, lo que hace que ante una determinada conducta individual sea apreciada por los otros individuos, como previamente acordada o codificada (in code), o totalmente desacertada o fuera de código (out code). Como es de prever, en la primera situación la conducta será aceptada como algo habitual que sigue los usos y costumbres de esa sociedad-cultura, mientras que en la segunda situación será rechazada por los demás, por considerarla de mal gusto o fuera de lugar, lo que normalmente terminará por generar algún tipo de conflicto, pelea o disputa.

Como se pueden apreciar en este análisis a partir de la aplicación del cuadrado de Greimas los dos sitios de investigación del marketing esencial ya sea para el mercado doméstico como para los mercados internacionales son: la mente del mercado hacia la derecha del esquema gráfico, y la mente del consumidor a la izquierda del mismo.

Figura 3. Los cuatro aspectos basales del marketing internacional

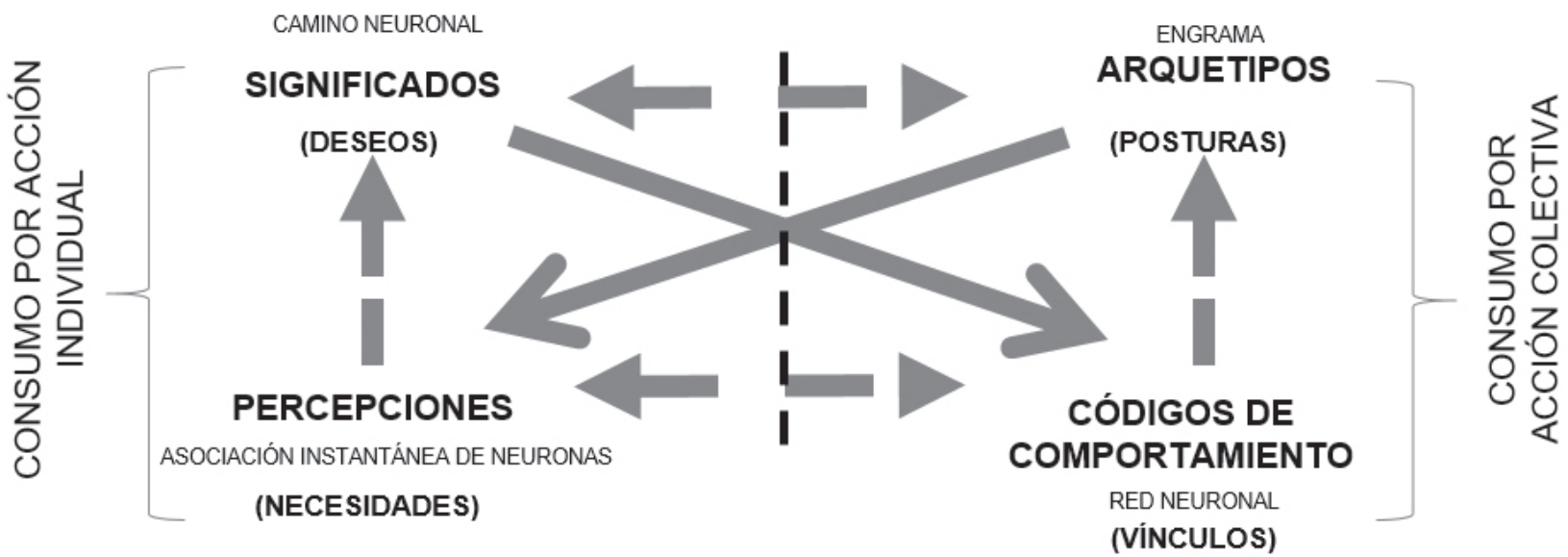

En esta aplicación gráfica de la Figura 3, también podemos apreciar que al repetirse en el tiempo las mismas percepciones, estas tienden a generar nuevos significados en la mente del consumidor (flecha hacia arriba). Tal como lo afirma el autor Lewis (2015) "de manera compulsiva, continua y sin esfuerzo, el cerebro transforma datos sensoriales en impresiones que tienen significado y los archiva en su 'propia cajita' dentro de la memoria" (p.119). Mientras que, en el sector de la mente del mercado, cuando los códigos de comportamiento son mantenidos vigentes por sucesivas generaciones de una determinada sociedad-cultura, a lo largo del tiempo, éstos tienden a conformar nuevas figuras arquetípicas en dicha mente del mercado. 


\section{Los aspectos movilizadores en la mente del consumidor, el impacto en la adaptación o estandarización}

En la mente del consumidor es en donde se manifiestan las percepciones las que actúan sobre las necesidades (motivador de compra básico y primordial). Estas necesidades provienen de los mandatos del cuerpo, mente, alma y hasta del entorno social del hombre. Tan o más importante aún es que en la misma mente del consumidor también se gestan los deseos, lo que siempre están apoyados por los significados propios. Al deseo lo podemos considerar el hijo de la necesidad y si se quiere, es también el padre de la expectativa. Todos estos aspectos derivan en las preferencias, gustos, caprichos y motivaciones de compra del individuo. También es el campo de los 'insigths' (visión interna del individuo) y sus drivers (activadores de compra).

Ahora, para ambos aspectos analizaremos como los mismos impactan directa o indirectamente sobre las políticas de adaptación y de estandarización, para lo cual haremos una breve presentación de cada tema y luego propondremos la discusión que nos convoca.

\subsection{La percepción en la base de la necesidad}

Sin dudas, que la percepción ha sido y será un aspecto determinante del marketing, ya que por este proceso el individuo adquiere nueva información del medio. A tal punto que incluso se lo puede considerar el 'input' de la mente humana, aunque también es causa de muchos de los sesgos mentales de las personas, ya que todo lo percibido por el hombre es tomado como realidades absolutas por el mismo, y hoy sabemos con certeza que no hay realidad alguna en la mente de las personas, ya que nuestra mente cambia las cosas por las propiedades fenomenológicas. Por ejemplo, sabemos por los fenómenos de la percepción amodal que a un objeto semi-oculto lo podemos percibir íntegramente, aunque en nuestra visión aparezca solo parcialmente visible por estar yuxtapuesto con otras cosas. A este fenómeno la Gestalt lo llamó 'el error de la experiencia', y desde su óptica los miembros de la escuela cognitivista denominaron a este fenómeno como 'procesos guiados por los datos', o, simplemente, pre-atencionales. Por su lado James Jerome Gibson (1974) en su obra clásica La percepción del mundo visual refutó que la percepción fuera un fenómeno indirecto para adoptar una postura basada en la percepción directa del hombre. La estrategia central del enfoque ecológico de Gibson afirma que al momento de describir el estímulo disponible para la percepción se debe distinguir entre sus dos componentes: 'energía del estímulo' e 'información del estímulo’. Según este autor en el estímulo está la energía, pero también la información, sin requerirse pensamientos internos posteriores. Dicho planteo parte del supuesto de que en las leyes naturales subyacentes en cada organismo están las claves intelectuales de la percepción como mecanismo de supervivencia, por lo tanto, el organismo solo percibe aquello que puede aprender y le es necesario para sobrevivir. El enfoque ecológico al concebir al input de la percepción como información, además de solo energía, el estímulo ya no requiere prácticamente de interpretación posterior, sino que es más directo (por lo tanto, no depende solo de la sensibilidad del sentido o sentidos involucrados), lo que posibilita, la construcción de una explicación directa de la percepción como un mecanismo humano de la interpretación del entorno. 
Podemos definir a la percepción como el conjunto de procesos y actividades relacionados con la estimulación que se alcanza con alguno o varios de los sentidos, mediante los cuales obtenemos información coherente con respecto a nuestro entorno, así como de las acciones que efectuamos en él y con referencia a nuestro sistema de referencias internas. De esta manera, se puede visualizar a la percepción como una imagen mental que se forma con la ayuda de la experiencia basada en el conocimiento previo y en las necesidades particulares del individuo.

La percepción trabaja entonces con los estímulos cerebrales logrados a través de los cinco sentidos (oído, tacto, vista, olfato, y gusto), los cuales generan una aparente realidad física del entorno a partir de dichos estímulos externos ya convertidos en sensaciones sentidas, las que producen en la mente humana finalmente la percepción. Por lo tanto, es la capacidad de recibir por medio de todos los sentidos, sensaciones, impresiones o las imágenes, para interpretar algo, por lo cual toda percepción incluye búsqueda, selección y procesamiento para obtener cualquier tipo de información. Pues, la percepción se da justamente en el límite entre lo consciente y lo inconsciente, pero se vuelve consciente cuando la podemos reportarla. También se da entre el cruce del sistema de referencias externo (a partir de rumores, publicidad, comentarios, comunicación, etc.) con el sistema de referencias interno (recuerdos, episodios, experiencias, significados, conocimientos, etc.). Sin embargo, como lo afirma el neurocientífico argentino Sigman (2015): "la percepción tiene siempre algo de imaginación. Se parece más a pintar que ha fotografiar. Y, de acuerdo con el efecto confirmatorio, creemos ciegamente en la realidad que construimos" (p.98).

Podemos finalmente definir a la percepción como el proceso mental y cognoscitivo, a través del cual los individuos captan la información del entorno y la interpretan directa o indirectamente (dependiendo de la carga informativa de la misma). Y es a partir de los sistemas sensoriales que llega dicha información al individuo, la cual es confrontada con su sistema de referencias internas y de esta manera, se busca lograr conformar una representación o imagen coherente del entorno que en muchas ocasiones es tomada como real. Por lo tanto, se caracteriza por su subjetividad, selectividad y temporalidad, ya que las percepciones son imágenes instantáneas. Aunque, a decir verdad, es cierto, que se parecen "más a dibujos que a fotografías". Podemos afirmar que es subjetiva ya que la respuesta que genera por un mismo estímulo varía de un individuo a otro; es temporal, ya que es un fenómeno a corto plazo definido por una asociación instantánea de neuronas y, por lo tanto, no es permanente ya que terminado el estímulo prácticamente desaparece la percepción; y es selectiva ya que depende de las necesidades, intereses y motivaciones que mueven a los individuos, es decir, percibimos lo que queremos percibir en una determinada circunstancia.

Además, por la acción emocional de las personas hace que se expanda o reduzca el campo de la percepción. Por ejemplo, en un asalto a mano armada, las personas asaltadas prestan tanta atención a la pistola, por el impacto emocional que esta genera a través del miedo, que se pierden el resto de los detalles de la escena. Por lo que es el individuo el que selecciona el campo perceptual en función de lo que se quiera percibir. Lo cierto es que percibimos lo que queremos o necesitamos en cada momento de nuestras vidas, si lo que apreciamos es agradable, expandimos nuestro campo de percepción, si lo que percibimos es desagradable, lo reducimos notablemente. En esos 
casos lo demás pasa a fondo o lo descartamos. Para percibir algo se tiene que dar que el sujeto haya generado un 'input' interno de requerimiento, por ejemplo, 'tengo sed'. O bien haya sido impactado por un estímulo con muy alta intensidad o por encima del umbral medio o vinculado con alguna aversión o placer.

Está claro que percepción siempre es previa a la significación, e incluso puede haber percepción sin significación alguna. Como ejemplo presentamos el fenómeno psicológico de la pareidolia, el que consiste en una capacidad ancestral de percibir rostros, figuras o hipotéticas amenazas en ciertos lugares a veces muy curiosos o que nada tienen que ver con la realidad, como ser: la arquitectura o fachada de un edificio, el capot o frente de un vehículo, la parte de atrás de un reloj despertador, la resaca en el fondo de una taza de café o té, las caprichosas formas que toman las nubes, etc. Como anticipamos este fenómeno es ancestral y estaría vinculado con la capacidad innata del hombre de detectar amenazas en ambientes salvajes o de alguna manera hostiles.

Habiendo hecho una breve síntesis del fenómeno de la percepción, ahora nos toca analizar si este concepto se puede considerar homogéneo en todas las culturas y naciones o por el contrario si se comporta de manera muy diferente. Pues bien, como el fenómeno tiene dos componentes su carga informativa y su intensidad o energía de impacto. Se aprecia con claridad que la primera está más ligada a la cultura local y a su cosmovisión, mientras que su segunda componente es más universal ya que la energía de la carga perceptiva solo apunta al nivel de atención del individuo. Aunque la sensibilidad a la captación de dichas intensidades energéticas pueda tener algunas variaciones en las distintas etnias y naciones que componen nuestro mundo, en general cuando la intensidad de un estímulo está por encima del nivel de los estímulos circundantes, entonces este estímulo se impondrá por sobre los demás (Ley de WeberFechner). En general el impacto de un determinado estímulo perceptivo, seguramente va a lograr la atención del espectador en todas las naciones y culturas, aunque esto no quiera decir que el mismo vaya a producir un efecto positivo o negativo en el mismo. $\mathrm{O}$ sea, este mecanismo de llamar la atención se puede considerar universal y apoyaría a la política de estandarización. Ahora, desde la carga informativa que trae la percepción como unión instantánea de neuronas, dependerá de las experiencias previas, de las sensaciones acumuladas en la memoria episódica, y en la cosmovisión de su cultura y sociedad. Por lo que no se podrá considerar tan universal, y esta característica sugiere una inclinación más clara hacia la política de adaptación. Por ejemplo, Bimbo® utiliza como su principal argumento de ventas e incluso en su eslogan los conceptos perceptivos de 'tierno y fresco', ideales para los países latinos, pero para naciones más frías o nórdicas del globo, el ideal en el pan es 'caliente y crocante'.

\subsection{El significado en la base del deseo}

El otro aspecto esencial de la mente del consumidor, se encuentra en las memorias límbicas, allí se aloja el 'universo de los significados'. Luego de que las cosas del ambiente adquieren sentido para el hombre a partir de las sucesivas percepciones, éste las significa, es decir, les otorga un significado. Y al hacerlo aloja a dicho significado en alguna de sus memorias del inconsciente. Su importancia radica en que es por estos significados que el hombre se maneja mediante la experiencia y sus conocimientos, a tal punto que algo que ya ha sido significado, no requiere de interpretación 
alguna, sino más bien que, a partir del estímulo y su recepción, se hará aflorar desde el inconsciente el significado o los significados asociados con la cuestión presentada y así conformar las ideas mentales relacionadas. Es decir, la mente humana funciona como un enorme 'banco de significados' que son atesorados en el cerebro y son también responsables de buena parte del consumo. Como lo afirma Lewis (2015) "los consumidores hacen las compras para satisfacer sus necesidades. Pero, van de compras para satisfacer sus deseos" (p. 37). Es decir, el capitalismo le da al deseo el rol del motor impulsor de la compra vinculado al significado. Muchos de esos significados cuando son generados y estimulados con una fuerte carga emotiva o emocional, logran perdurabilidad gracias a su importante carga energética, que incluso los mantendrá activos a lo largo de toda su vida. En esos casos, estos significados adquieren las características de improntas. En el sentido contrario, cuando los significados son creados en la mente con cargas energéticas débiles y sin estímulos posteriores, tienden a desaparecer o a re-significarse.

El marketing esencial ya sea doméstico o internacional parte de la base de que todos los productos y servicios deben ser interpretados desde el significado creado en la mente del consumidor. Estos significados fueron generados en algún momento de la vida de dicha persona, y hoy sabemos, gracias a la psicología, que la gran mayoría de los significados cotidianos fueron creados en los primeros siete años de vida (son los que utilizamos de manera automática en el día a día). También desde nuestro paradigma de marketing esencial se avala el hecho de que con el tiempo las personas pueden cambiar sus significados (proceso de re-significación), y estos significados hasta pueden desaparecer por el fenómeno de la abruption, ya que también sabemos que los recuerdos de los consumidores son en realidad mucho más creativos y dúctiles de lo que normalmente se piensa.

Por otro lado, gracias al trabajo del psicoanalista francés Lacan (2007), podemos afirmar que los significados cambian constantemente por cuestiones circunstanciales o de contexto sin que incluso lo podamos controlar.

Ahora, desde el punto de vista neurocientífico por el trabajo del portugués Damasio (2004) sabemos que fisiológicamente un significado se constituye como un camino neuronal creado por neuronas interconectadas a través de la sinapsis, todo esto a partir de la acción de distintos neurotransmisores que interactúan para conformar ese significado. En definitiva, en lo que sí todos los autores concuerdan es que un significado no es una cosa o algo concreto, sino la representación psíquica de la cosa.

Ahora, como antecedente teórico debemos citar al sociólogo Blumer (1982), quien desde el interaccionismo simbólico presentó ya en 1937 sus postulados en donde prácticamente presentaba la importancia de trabajar con los significados como base de todo plan social, y que nosotros trasladamos a nuestro paradigma de marketing esencial:

1. Los humanos actúan respecto de las cosas sobre la base de las significaciones que estas cosas tienen para ellos, o lo que es lo mismo, la gente actúa sobre la base del significado que atribuye a los objetos y situaciones que le rodean.

2. La significación de estas cosas deriva, o surge, de la interacción social que un individuo tiene con los demás actores. 
3. Estas significaciones se utilizan como un proceso de interpretación efectuado por la persona en su relación con las cosas que encuentra, y se modifican a través de dicho proceso (p. 79).

Herbert Blumer ya en 1937 anticipaba que para la determinación de significados se requeriría de una metodología eminentemente distinta, lo que dio pie al desarrollo de nuestras 'técnicas de afloramiento de significados'. Pues sin dudas, estas técnicas de afloramiento de significados responden a estos postulados (París, 2015b).

Para resumir, daremos una definición de significado, como el aspecto esencial del marketing, por lo cual podemos afirmar que el significado es toda interpretación que una persona de una determinada sociedad, cultura y en un determinado tiempo, e incluso en una determinada circunstancia, le dará a un conjunto de conceptos materiales, inmateriales o combinación de ambos. Es la representación psíquica de la cosa. Es una creación pura de la mente humana.

Desde el punto de vista de las políticas de estandarización versus adaptación del marketing internacional, se aprecia que los significados creados por las distintas culturas a partir de sus individuos, son los principales obstáculos para las políticas de estandarización. Aunque pareciera que el conocimiento que se tiene en el mundo sobre las cosas, fuera en realidad muy similar, la forma en que los mismos fueron estructurados, no lo son. Sobre todo, para aquellos productos en que el libre albedrío y la libre determinación del individuo están vinculados con las culturas locales o nacionales. Ambos aspectos, también hoy son muy cuestionados. Ya sea por lo simple que en realidad resulta manipular la mente humana, y de la misma manera al inconsciente colectivo; pero también por los mismos automatismos e incluso por la misma miopía del consumidor, así como por los numerosos sesgos mentales (París, 2019). Como los significados son privativos en el proceso de búsqueda, selección, evaluación y compra de cada individuo, entonces se vuelven esenciales para todo plan de marketing internacional. Por ejemplo, el cuy o cobayo, en Argentina significa mascota simpática y muy apreciada por los niños; mientras que en Ecuador significa manjar exclusivo del emperador inca, muy apreciado por los comensales por lo exquisito de su carne, y utilizado para agasajar a un invitado especial.

\section{Aspectos movilizadores en la mente del mercado, el impacto en la adaptación o estandarización}

Pareciera ser que la obsesión por el consumo en el mundo capitalista implicara escalar esa 'escalera al cielo' hacia el logro de los deseos personales, lo que hace que cada persona actúe de manera autónoma, incluso despreocupándose de los intereses del resto del mundo humano. Lo cual, pareciera ser una jungla, en la que el 'sálvese quien pueda', se presenta como la única ley, aunque existe un elemento que mantiene alejada a la humanidad del caos, que implica esta suma informe e infame de individuos egoístas. Se trata del inconsciente colectivo, el que de alguna manera nos induce a comportarnos socialmente, y actúa como una fuerza invisible que nos lleva a relacionarnos con los otros. Es decir, los mercados poseen una mente, que conduce a la conducta social a partir de valores humanos y una ética común regida por reglas de convivencia. Este 
inconsciente colectivo actúa como una especie de fuerza magnética que tiende a alinear los intereses personales con los intereses colectivos de todas las personas.

Fue Karl Gustav Jung (1984a) quien mejor desarrollara la idea del inconsciente colectivo y este autor lo define como la "herencia psíquica", y lo presenta como un tipo de conocimiento o imágenes ancestrales con el que todos nacen, se comportan y comparten entre sí sin cuestionamiento alguno. Según Jung estas imágenes son heredadas en la estructura del cerebro, y producen remotísimos modos de ver. Incluso explicarían el por qué muchas naciones distintas poseen similares leyendas y mitos a pesar de miles de kilómetros entre sí y sin haber tenido contacto alguno en sus pasados. Esto nos conduce a la idea de que podamos diferenciar entre dos capas mentales del inconsciente, una personal y la otra colectiva. El problema subyace cuando los intereses de la persona van en sentido diferente del de su grupo social, en esos casos se da la disonancia cognitiva, según Lewis (2015) "la disonancia cognitiva puede definirse como la sensación de incomodidad que experimentamos cuando intentamos sostener al mismo tiempo dos creencias que al enfrentarse presentan un conflicto" (p. 44).

Siendo que el inconsciente colectivo está dotado de propósito e intencionalidad, cuya fuerza energética reposa en elementos primordiales o arcaicos, llamados "arquetipos", pero también en forma de "códigos de comportamiento", los que a su vez se dividen en "códigos simbólicos" y "códigos culturales", aspectos que no se pueden tomar a la ligera. Pues, sabiendo que tanto los arquetipos como los códigos de comportamiento rigen muchas de nuestras acciones en la vida cotidiana e incluso en nuestra actividad social, laboral, intelectual, profesional y cultural, ya que tienden a alinear nuestro comportamiento con el de los demás. Y cuyo correlato neurocientífico son los engramas del cerebro reptílico ${ }^{1}$ para los arquetipos, y de redes neuronales para los códigos de comportamiento. Por ejemplo, cuando nos subimos a un bus para realizar un largo viaje hasta nuestros hogares luego de un duro y agotador día de trabajo, actuamos de acuerdo con alguno de los dos siguientes arquetipos: 'egoísta' o 'cortés', dependiendo de si en su interior hay mujeres o solo hombres y si hay mujeres con infantes o personas mayores y del nivel de agotamiento físico del individuo se actuará con uno u otro arquetipo. Al activar a una de estas posturas prácticamente dejamos de lado a la otra, y será muy difícil que cambiemos sobre la marcha, pues hemos adoptado una postura. Por lo cual, estos aspectos rigen buena parte del 'día a día' de las personas en su comportamiento social, y en particular en el de consumo, por lo cual es imprescindible que el marketing internacional se ocupe de estos aspectos esenciales de manera eficaz y comprometida, ya que son responsables de muchas de nuestras acciones cotidianas vinculadas con nuestro estilo de vida y del consumo social y cultural. Pues a través de nuestro paradigma de marketing esencial hoy sabemos que las cuestiones del inconsciente colectivo del mercado, actúan como una fuerza invisible, pero determinante que re-direcciona los comportamientos finales del consumidor en el momento de la verdad, es decir, al momento de tomar sus decisiones de compra.

1 Un engrama es una estructura muy compleja de redes de interconexión neuronal estable que producen respuestas automáticas incluso del comportamiento, pues los engramas psíquicos son ejecutados mediante la actuación consciente del individuo. 
Por lo que, en el segundo espacio de investigación, es decir, la mente del mercado, determinaremos los siguientes aspectos: los arquetipos y los códigos de comportamiento.

\subsection{Los arquetipos como base de la postura}

Como el mismo Jung (2005) lo afirma, un arquetipo posee las siguientes características que lo definen:

No se trata, pues, de representaciones heredadas, sino de posibilidades heredadas de representaciones. Tampoco son herencias individuales, sino, en lo esencial, generales, como se puede comprobar por ser los arquetipos un fenómeno universal. (párr. 3)

Como vimos anteriormente los arquetipos funcionan como verdaderas cajas vacías (pre-conformadas y que todos poseemos), las que se pueden cargar con energía positiva o negativa dando resultados absolutamente opuestos. Por ejemplo, dependiendo de la información que maneja una persona sobre un determinado tema, si ésta posee argumentos científicos sobre la temática en cuestión, esta persona puede ser considerada 'sabia' que es una connotación arquetípica positiva. Ahora, esta misma persona cuando desconoce la temática en cuestión, pero sin embargo opina sin fundamentos o argumentos válidos, asumirá el personaje arquetípico del 'charlatán'. La cual sería la parte oscura de la misma caja vinculada con el saber del individuo. Por lo tanto, las figuras arquetípicas pueden ser requeridas para identificar determinados aspectos del comportamiento humano y en particular del consumo (los que incorporan determinadas posturas de personajes). Lo interesante de las figuraciones arquetípicas es que son reconocidas por todos los individuos, incluso pertenecientes a sociedades y culturas diferentes.

Ahora bien, para determinar los arquetipos definidos por Jung (1984b) hemos promovido en nuestros libros la utilización de las técnicas de investigación proyectivas, así como la aplicación de las grillas de los opuestos semánticos entre otras herramientas (París, 2015b).

Para tratar este apasionante tema, vale la pena hacerse la siguiente pregunta: ¿qué son los arquetipos? Para Jung los arquetipos son los remanentes arcaicos o imágenes primordiales, es decir, representaciones inconscientes. Los arquetipos son estructuras del inconsciente colectivo. Algunos de ellos son en su lado positivo-negativo: madre-madrastra, padre-tutor, héroe-cobarde, amigo-traidor, ídolo-fracaso, déspota-mártir, profeta-farsante, sabio-charlatán, sacerdote-brujo, santo-demonio, etcétera, pero un aspecto común entre ellos es que los mismos están presentes en prácticamente todas las sociedades y culturas, ya que de alguna manera las sociedades y sus culturas convergen hacia estas figuraciones arquetípicas.

Un aspecto destacable del arquetipo es que no posee una forma en particular, pero funciona como un 'principio organizador' sobre las cosas que vemos o hacemos y determina un curso de acción cuasi automático. Por eso Jung se refiere a ellos como especies de 'cajas', o como moldes que están en nuestra mente y son parte de nuestro ser. Y cuyo contenido se pueden cargar con energía positiva (lado claro del arquetipo) o con energía negativa (lado oscuro o sombra del arquetipo). Por ejemplo, el héroe y el cobarde comparten la misma caja y se pueden activar con cualquiera de las dos energías dependiendo las circunstancias que se presenten. Para aclarar este aspec- 
to, supongamos una misma persona, ésta cargará de forma positiva a dicha caja y se convertirá en héroe en un accidente aéreo (porque fue instruido para este tipo de accidentes y sabe qué hacer y posee la energía para hacerlo); pero ante el eminente hundimiento del buque en el que está navegando actúa como un cobarde al tratar de salvarse primero, ya que no sabe nadar y le tiene pánico al agua. Como se aprecia en este caso supuesto, la energía con la que cargamos a dicha caja dependerá de la situación que se le presente al individuo y de su experiencia y conocimientos previos. Carl Gustav Jung (1984a), lo explica de la siguiente manera:

Los contenidos del inconsciente personal son en lo fundamental los llamados complejos de carga afectiva, que forman parte de la intimidad de la vida anímica. En cambio, a los contenidos de lo inconsciente colectivo los denominamos arquetipos. (p.10)

Como lo afirma Pepe Martínez (2008):

Los arquetipos son símbolos que representan relaciones especialmente significativas para el ser humano. Por ejemplo, el héroe es el modelo arquetípico del valor y del coraje. Los arquetipos son referentes universales, es decir, íconos consistentes a través del espacio (diferentes países y valores) y del tiempo (distintas épocas históricas). (p. 69)

Por este aspecto del arquetipo desde el punto de vista de las políticas de estandarización versus adaptación, se puede considerar como el principal aliado de las políticas de estandarización, y esto es por una de sus principales características ya identificadas por Jung. Los arquetipos se dan en todas las culturas, y los mismos son similares. Por lo que es lícito usar la figura del héroe en una publicidad vinculada con la venta de un limpiador de inodoros, por lo menos en el mundo capitalista.

\subsection{Los códigos de comportamiento como base del vínculo}

Los códigos de comportamiento funcionan como una red de significados interrelacionados que cumplen la tarea de filtrar las conductas y comportamientos de las personas. Es decir, se los puede describir como filtros 'pasa-no pasa' de la conducta humana, por el cual, están conformados como constructos o patrón de significados interconectados en redes neuronales llamadas códigos simbólicos o los códigos culturales. El primero de estos códigos es manejado fundamentalmente con símbolos naturales (estos derivan de los contenidos inconscientes de la psique) y, por lo tanto, representan un número enorme de variaciones de las imágenes primitivas y esenciales manifiestas en los gestos, ademanes y posturas corporales que son en general de fácil interpretación. Muchos de ellos tienen raíces arcaicas y se puede seguir su rastro en las sociedades más primitivas, a tal punto, que incluso algunos primates superiores se manejan con estos tipos de códigos simbólicos. De hecho, cuando un gorila alza sus brazos y golpea sus pechos, está usando un tipo dominante de código simbólico; tal como lo hacen dos personas que se amenazan moviendo sugestiva y violentamente sus brazos durante una disputa en ocasión del choque de sus carros.

Por su lado el código cultural se produce cuando una persona utiliza fundamentalmente conceptos y rituales culturales que son aquellos que se han empleado para manejar esas 'verdades' que provienen del quehacer del hombre en su búsqueda de la realidad. Y lo hacen a través del conocimiento por medio de la ciencia, el arte, la religión y otras formas de comunicación cultural. Ahora, cuanto más racionalmente 
actúen las personas, cuanto más controlen sus emociones, y cuanto mayor cantidad de argumentos se utilicen más prioridad se les dará a los llamados 'códigos culturales' cuyo origen obviamente se encuentra en la cultura, que es definida como la personalidad de una determinada sociedad.

Desde el punto de vista neurocientífico los códigos de comportamiento son redes neuronales conformadas por caminos neuronales que se han ido entrelazando por la acción de un grupo de neuronas dopaminérgicas, tal como lo explica Jonah Lehrer (2011) lo interesante acerca de este sistema es que todo tiene que ver con las expectativas. Las neuronas dopaminérgicas generan continuamente patrones basados en la experiencia: si tal, entonces cual. Este mismo autor afirma que la evolución nos ha programado para que nos preocupemos los unos de los otros a través de los vínculos, de ahí la importancia de generar constructos mentales en forma de códigos de comportamiento que faciliten y ordenen la convivencia humana en armonía.

El autor francés Clotaire Rapaille (2007) nos indica que las distintos comportamientos, costumbres, usos y hábitos que poseen las distintas sociedades y que se crean entre culturas diferentes, en realidad no están definidas tanto por el conocimiento con que éstas manejan o disponen, sino más bien, por la forma en que los conocimientos se estructuraron, incluso a veces por cuestiones circunstanciales, casuales o fortuitas.

En particular vemos al código de comportamiento como un patrón de significados interrelacionados mentalmente entre sí, el que forma un entramado que actúa como si fueran los elementos filtrantes de la conducta social y cultural. Lo cierto es que con ellos nos manejamos en la vida cotidiana y a través de ellos generamos vínculos con los otros, filtrando permanentemente la información del ambiente, tomando solo aquello que ha recibido un 'mandato' y que proviene de lo profundo de nuestro inconsciente colectivo y que se trasmutando a nuestra vida cotidiana, ya que de ellos se rigen prácticamente todos nuestros actos sociales y culturales.

Ahora bien, desde los comportamientos religiosos, militares, académicos, teatrales, etc. hasta las acciones de un cliente en una tienda, así como los ademanes, los gestos o las costumbres en la mesa, se trata de comportamientos ritualizados, que son codificados y asumidos por las sociedades como habituales o naturales. En dichos códigos, como lo hemos descripto participan cantidad de significados, y como los significados son culturales, los códigos también lo son, por lo que son propios de cada sociedad. Por lo que se vuelve totalmente válido estudiar desde el marketing internacional estos ritos en el momento en el cual se están gestando y lo hacemos mediante las metodologías que nos ofrece la antropología como lo es a observación. El conjunto de códigos de una determinada sociedad es lo que define los filtros a través de los cuales percibe, interpreta y entiende su mundo en el día a día, y es lo que nos suele incomodar cuando llegamos a un país diferente, justamente el desconocimiento de sus códigos. Dentro de una determinada sociedad y en una determinada cultura los códigos se convierten en patrones colectivos que se transfieren de una persona a otra a través de las generaciones (a veces con algunos cambios semánticos con las adaptaciones contextuales correspondientes, y rara vez con cambios estructurales o de fondo). Los códigos son las claves del comportamiento de las distintas colectividades y etnias, por lo que si se quieren entender habrá que interpretarlos a partir de descifrar que se busca a través de los mismos, ya que este conocimiento no está escrito en ningún sitio. Ahora, si se interpretan los vínculos sociales que persiguen dichos códigos y tiende este 'puente 
de oro' con el mercado y sus consumidores se podrá lograr una alineación estratégica con el código de la mente del mercado, y entonces la comunicación estará alineada o 'in-code'. En este caso, el consumidor (sujeto de la demanda) verá cómo las promesas de las empresas son compatibles con sus ilusiones. Y de esta manera los mensajes de la oferta (objeto de la oferta) generarán la respuesta deseada. Pero, cuando los elementos perceptibles no concuerdan con el código, entonces habrá disonancia, la que se traducirá en un fuerte rechazo por parte del consumidor. En estos casos diremos que la promesa de la oferta estará desalineada o 'off-code' (fuera de código).

Desde el punto de vista de las políticas de estandarización versus adaptación, los códigos de comportamiento cuando rigen el consumo, requieren ser analizados en profundidad, pues en general reportan cambios en las distintas culturas, por lo cual se convierten en un verdadero problema para los intentos de estandarización. Por ejemplo, el ritual del consumo de coñac es muy diferente en México, Colombia y Argentina. México se lo toma frío y con soda o agua, en Colombia a temperatura ambiente y con fondo seco, y en Argentina el ritual exige calentar la copa con un mechero y beber el coñac mediante sorbos cortos mientras se conversa. El producto es el mismo, pero sus códigos de comportamiento varían incluso entre las mismas sub-culturas latinoamericanas.

\section{El comportamiento del consumidor desde el paradigma del marketing esencial}

En gráfica de la Figura 4 se aprecia cómo el estilo de vida del consumidor se nutre a partir de la propia personalidad y de su cultura, y además se puede visualizar cómo los atributos deben relacionarse con los valores personales y sociales del individuo para conformar los nuevos productos y servicios de la oferta para que la orientación a la compra facilite la acción comercial de la empresa.

Figura 4. Los valores y el estilo de vida del consumidor

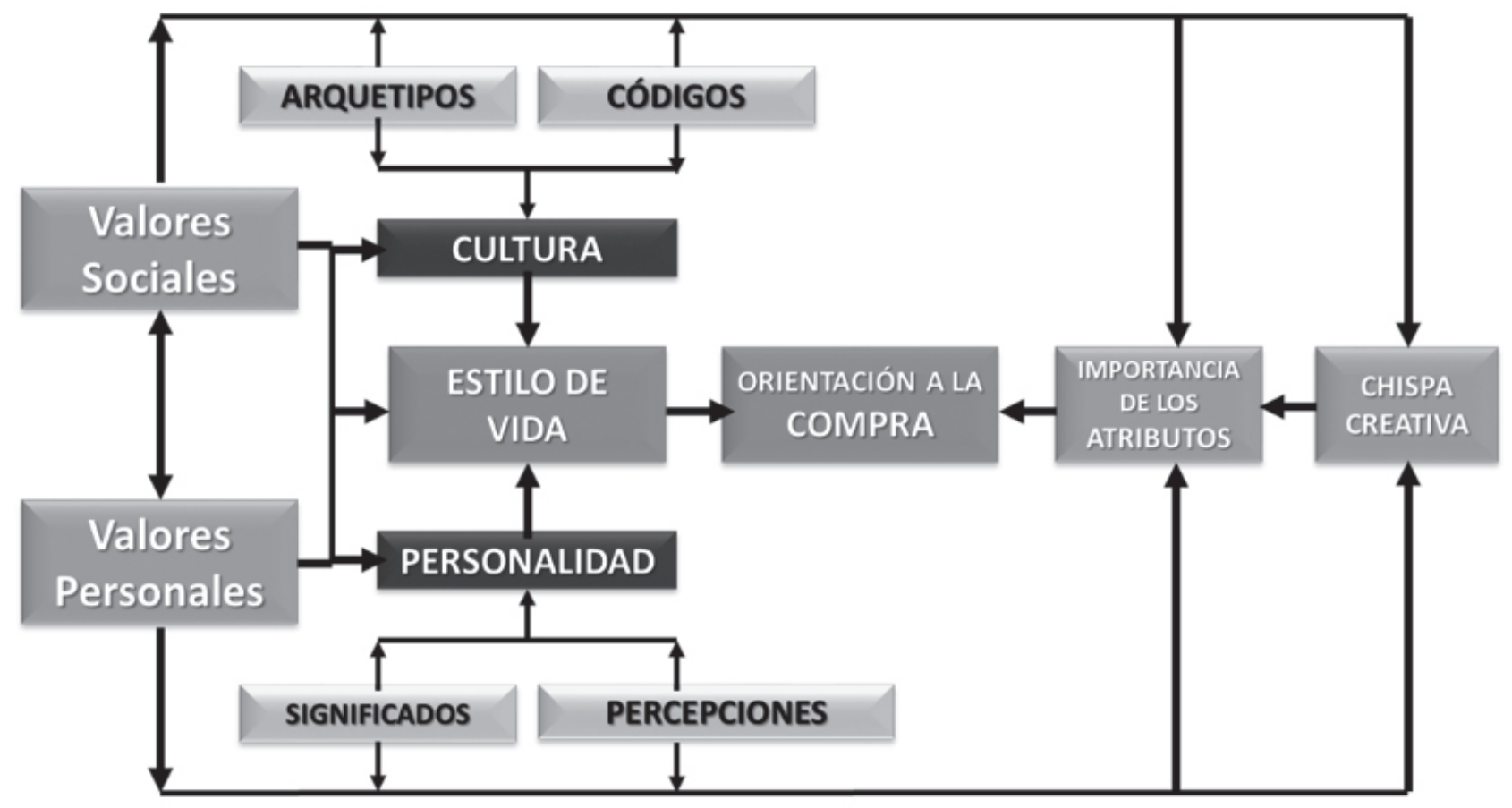


En el esquema gráfico de arriba se puede apreciar que desde nuestro paradigma de marketing esencial presentamos un modelo de gestión de negocios que se basa en la investigación de: percepciones y significados que se montan sobre las necesidades y los deseos, por un lado; y los códigos de comportamiento y los arquetipos que se montan sobre los vínculos y las posturas, por el otro. También se aprecia en dicho esquema gráfico que los valores son precedentes del estilo de vida y actúan como elementos determinantes tanto de los aspectos y principios personales como de los sociales a través de la ética. Entonces, si se cancelan los valores, como consecuencia de ello se perdería la identidad, pues esta está ligada a una determinada cultura (la que puede ser vista como la personalidad de una determinada sociedad) y claro está a esto se le suma la propia personalidad del individuo.

Uno de los aspectos que más se ha tratado de interpretar es el denominado código de comportamiento del comprador o patrón de conducta de compras, también denominado en la literatura del marketing como patronage. En el modelo de la Figura 4 inspirado en el trabajo de Carman (1978) se aprecia como los valores influencian un determinado patronage o modelo de conducta del consumidor. Como lo afirma Francisco Saravia (2009):

Los valores se convierten en las causas de los intereses de las personas y que éstos asuman una serie de roles que, a su vez, son el motivo de las actividades en las que invierten su tiempo. Cada conjunto de variables (valores terminales, valores instrumentales, intereses, roles y actividades realizadas en tiempo libre) influye en el comportamiento de compra. (p.49)

Nosotros agregamos a este enfoque, que además del rol del investigador con sus metodologías, también se le debe sumar la propia chispa creativa del mercadólogo. Esta es esencial para otorgarle un toque de distinción al plan de marketing, pero siempre sobre la base de lo investigado tanto en la mente del consumidor, como en la mente del mercado.

\section{Análisis del consumidor desde el paradigma esencial para su aplicación internacional}

Es de esperarse que un nuevo paradigma de marketing requiera de una nueva metodología de investigación. Incluso hoy más aún, cuando son muchos los autores que han estado criticando la metodología tradicional de análisis del consumidor e investigación de mercados. Sobre todo, desde el momento en el que autores como Clancy y Shulman (1998) quienes, en su libro de principios de la década del noventa, la revolución del marketing, ya anticipaban que la revolución del marketing no se iba a gestar por los nuevos datos o la nueva tecnología (aunque unos y otra contribuirán a ella).

En realidad, la información es el insumo y la tecnología es la herramienta, los insumos siempre aportan, las herramientas cambian para adaptarse al momento, pero los conceptos son los que perduran. Luego de más de veinte años desde que ese libro fuera publicado, esta anticipada aseveración ha demostrado lo acertado de su predicción, pues estos autores ya criticaban de manera descarnada los sistemas de análisis del consumidor y las metodologías de investigación utilizadas. Incluso a principios del siglo XXI, el mismo Kevin J. Clancy, pero esta vez acompañado por Peter C. Krieg, en su libro Marketing, no intuición, insisten en que la mayor parte de las empresas no investigan bien, tal es así que los autores expresan lo siguiente: 
Creemos que este es el caso de muchos éxitos de marketing: el producto justo estaba en el lugar justo y en el momento justo. La intuición, la creatividad y 'atrapar la ola' fueron seguramente mucho más importantes que un proceso lógico o una investigación sólida en la obtención del resultado. (Clancy \& Krieg, 2004, p. 65)

Pero, las duras críticas siguen hasta nuestros días, por ejemplo, el neurocientífico danés Martin Lindstrom en su libro Compradicción (buy-ology) (2009) también afirmaba:

Ya en 2003 veía claramente que los métodos tradicionales de investigación de mercados o los grupos focales ya no servían para averiguar lo que realmente piensan los consumidores. Eso se debía a que nuestra mente irracional, atestada de prejuicios culturales arraigados en la tradición, en la crianza y toda una serie de factores subconscientes, ejerce una influencia poderosa, pero velada sobre nuestras decisiones. (Lindstrom, 2009, p. 21)

También desde nuestra experiencia como consultores de marketing tanto doméstico como internacional, supimos darnos cuenta que se exigía una metodología de análisis adaptada a los requerimientos que demandaban la determinación e interpretación de los cuatro aspectos esenciales y basales del plan de marketing: percepciones, significados, códigos y arquetipos. Y para ello sin ningún tipo de limitaciones nos permitimos desarrollar una metodología heurística, holística y con un marcado eclecticismo, sin que esto significara según las expresiones de Schütz (1999) una contaminación ideológica que implicaría utilizar métodos híbridos, ya que éstos son corruptibles y suelen confundir al investigador al momento de elegir metodologías subjetivas u objetivas y para terminar definitivamente con su dicotomía que tantas complicaciones han traído al mundo de la ciencia, por lo que Schütz nos invita a mantener la coherencia de la investigación y a pautar un esquema de investigación sin tomar caminos paralelos por más tentadores que nos parezcan. Es decir, Schütz nos invita a mantener la 'pureza del método'. Ahora, aunque nuestra metodología sea fundamentalmente empírica, no por ello descuidamos al método científico en su aplicación, tal como lo afirma el mismo Alfred Schütz (2012):

Debemos destacar que la descripción minuciosa de los procesos que permitan a un hombre comprender los pensamientos y las acciones de otro es requisito de las metodologías de las ciencias sociales empíricas. La cuestión de cómo es posible una interpretación científica de la acción humana puede ser resuelta únicamente si antes se dilucida de manera adecuada cómo puede el hombre, en la actitud natural de la vida cotidiana y el sentido común, comprender la acción del otro. (p. 33)

Por ello, en nuestra metodología de investigación nos hemos propuesto salir del estudio de las consecuencias de las acciones de los hombres, para tratar de determinar sus causas. Por lo tanto, nos interesa saber los 'para' y los 'por qué' hacen lo que hacen las personas. Lo que nos obligará a determinar estos 'para' y 'por qué' del consumidor, ya que nuestro campo de acción es el mercado y dentro del mismo, el hombre, en su rol de consumidor ya sea nacional o internacional.

\section{Integración de aspectos esenciales frente al análisis del consumidor}

Está claro que según nuestro paradigma de marketing esencial la decisión de la compra del consumidor tiene como epicentro basal alguno de estos cuatro motivadores ya presentados en este artículo, también es cierto que no siempre es tan fácil su 
identificación y en muchos casos pareciera ser que actúan varios de ellos de manera simultánea, aunque también es cierto que uno de ellos siempre es el determinante.

Un aspecto en el cual debemos poner cierto énfasis es que, si bien la metodología de investigación mercadológica esencial requiere de una mayor pericia, sin embargo, la aplicación del plan de marketing doméstico o internacional se simplifica notablemente ya que la determinación del motivador de compra esencial oficia como facilitador del marketing táctico. Para facilitar estas dificultades iniciales, hemos creado técnicas de investigación del consumidor especializadas, como es la técnica de afloramiento de significados, así como adaptado otras metodologías de investigación para interpretar las percepciones, códigos de comportamiento y las figuras arquetípicas dominantes, las que buscan darle al investigador una herramienta poderosa para acotar a esa apreciación. Estas técnicas las hemos plasmado en nuestro libro Investigación mercadológica esencial (París, 2015b).

Aunque debemos aclarar, que si bien seguramente acortaremos la brecha entre el significado en la mente del consumidor con la percepción que el investigador logre de la misma, igualmente seguirá siendo una percepción ya que la realidad siempre distará en algo de lo científicamente percibido por el hombre. Referenciado a Popper (1985), lo que estamos haciendo con estas técnicas y metodologías de investigación es tirar al 'mar de las realidades' redes de trama cada vez más fina, para así tratar de pescar una mayor cantidad de aspectos de dicha realidad y lograr así una mayor aproximación a la verdad, que en este caso está en la mente del mercado y del consumidor. Pero, debemos aclarar que aún seguimos asumiendo, que lo que recogerá el investigador especializado, seguirá siendo una percepción, aunque sea ésta más cercana a la realidad y seguramente también sea más profesional y eficaz, igualmente seguirá siendo una percepción. Ahora bien, somos conscientes que la decisión más racional no implica obtener los mejores resultados, porque en los asuntos humanos casi siempre interviene el azar y las conjeturas anticipadas movilizadas por el efecto confirmatorio y la negación de la varianza que también pueden entorpecer aún más los resultados. Pero, con la experiencia, la pericia y la cantidad de observaciones, la casualidad tiende a equilibrarse y a desaparecer. Pero, para ello el investigador debe estar libre de toda parcialidad e interés particular y ser un correcto implementador de las técnicas a los fines de no ser parte del mismo resultado. Por lo que la pericia es un requisito a la hora de aplicar las técnicas y metodologías de investigación aquí auspiciadas y que promovemos para determinar estos importantísimos cuatro aspectos del marketing esencial, fundamentalmente para su aplicación internacional.

\section{Discusión y conclusiones}

Como se aprecia en este artículo, aquí no hemos cuestionado si una política de estandarización es viable o no, o si se requiere de una adaptación por las consecuencias que esta política implicaría, tampoco se describieron argumentos en pro o en contra de ambas políticas, es decir, ni a favor ni en rechazando a las mismas. Lo que hemos hecho es analizar a través de las bases esenciales del plan de marketing internacional, si los cuatro aspectos esenciales impulsan o limitan el concepto de estandarización o adaptación. Tanto las percepciones y significados actuando en la mente del consumidor sobre sus necesidades y deseos; por un lado, como a través de los códigos 
de comportamiento y las figuraciones arquetípicas que actuarán sobre los vínculos y las posturas adoptadas por los individuos. Aquí es donde hallamos a las verdaderas causas que pueden apoyar u obstaculizar una u otra política. Quiere decir que desde el paradigma del marketing esencial afirmamos que son estos cuatro aspectos estratégicos los que pueden colaborar o que también pueden obstaculizar el desarrollo de una u otra política de marketing internacional. Y nuevamente volvemos a advertir que no identificar cuáles de éstos son los factores, que solos o combinados movilizan el consumo. Y no interpretarlos para luego trabajar con ellos desde la misma base de un plan de marketing internacional, es como trabajar a ciegas, sobre una base conceptual poco firme, y claro está, con muy pocas probabilidades de lograr el ansiado éxito mercadológico.

\section{Referencias}

Arduini, J. (2006). Antropología, atreverse a recrear la humanidad. Ed. San Pablo.

Audesirk, T., Audesirk, G., \& Byers, B. (2003). Biología, la vida en la Tierra. 6ta. ed. Pearson Educación. Blumer, H. (1982). El interaccionismo simbólico: perspectiva y métodos. Hora Editora.

Boddewyn, J., Soehl, R., \& Picar, J. (1986). Standarization in international marketing: is Ted Levitt in fact right? Business horizon, 29(6), 69-75.

Bruhn, M. (2004). Werbung und Kommunikation für international märkte. In: Brij Nino Kumar y Helmut Hausmann, Handbuch der internationalen unternehmenstätigkeit.

Buzzell, R. (1968). Can you standardize multinational marketing? Harvard Business Review, 49, 10213. https://bit.ly/2AYYcnh

Carman, J. (1978). Values and consumption patterns: a closed loop. Advances in Consumer Research, 5, 403-407.

Clancy, K., \& Shulman, R. (1998). La revolución del marketing. Javier Vergara Editor.

Clancy, K. y Krieg, P. (2004). Marketing, no intuición. Javier Vergara Editor.

Damasio, A. (2004). El error de Descartes, la emoción. 3ra. ed. Crítica.

Elinder, E. (1965). How international can european advertising be? Journal of Marketing, 29(2), 7-11.

Gibson, J. (1974). La percepción del mundo visual. Emecé.

Greimas, J. (1983). La semiótica del texto. Ejercicios prácticos. Paidós.

Huntington, S. P. (1997). El choque de civilizaciones y la reconfiguración del orden mundial. Ed. Paidós.

Jung, C. (1984a). El hombre y sus símbolos. $4^{\circ}$ Ed. Buc Caralt.

Jung. C. (1984b). Arquetipos e inconsciente colectivo. 2da. Reimpresión. Ed. Paidós.

Jung, C. (2005). Recuerdos, sueños, pensamientos. Ed. Seix Barrall.

Lacan, J. (2007). El Seminario 4, La relación de objeto (1956-1957). 1999, 6ª reimpresión. Texto establecido por Jacques Alain Miller. Paidós $1^{\mathrm{a}}$ edición.

Lehrer, J. (2011). Cómo decidimos y cómo tomar las mejores decisiones. Ed. Paidós.

Levitt, T. (1983). The Globalization of Market. Harvard Business Review, 61(3), 92-102.

Lewis, D. (2015). El cerebro vendedor. Editorial Paidós.

Lindstrom, M. (2009). Compradicción (buy-ology). Norma.

Kotler, P. (2005). Los 10 pecados capitales del marketing. Gestión 2000.com.

Madeira, A., \& Silveira, J. (2013). Internacionalização de empresas. Saint Paul.

Martínez, P. (2008). Cualitativa-Mente, los secretos de la investigación cualitativa. Esic.

McLuhan, M. y Powers, B.R. (1989). The global village. Oxford University Press.

Montserrat, J. (2001). Engramas neuronales y teoría de la mente. Pensamiento: Revista de investigación e Información filosófica, 57(218), 177-211.

Onkvisit, S., \& Shaw, J. (1987). Standardized international advertising: a review and critical evaluation of the theoretical and empirical evidence. Columbia journal of world business, 22(3), 43-55.

Papavassiliou, N., \& Stathakopoulus, V. (1997). Standarization versus adaptation of international advertising strategies: towards a framework. European Journal of Marketing, 31(7), 504-527. 
París, J. A. (2012). La segunda miopía del marketing. Ed. Haber.

París, J. A. (2015a). Investigación mercadológica esencial. Ed. Errepar.

París, J. A. (2015b). Marketing internacional desde la óptica latinoamericana. Edición UNLP-Errepar.

París, J. A. et al. (2016). Proyectos de investigación CONEAU-FCE-UNLP: E-133 (2013-2014) y E-149 (20152016).

París, J. A. (2019). Tendencias mercadológicas esenciales. Ed. CP67.

Peebles, D. M. (1978). Coordinating international advertising. Journal of Marketing, 42(10), 28-34.

Popper, K. (1985). La lógica de la investigación científica. Tecnos.

Postigo, S. (2014). Marketing de Empresas Born Global. El caso de las capacidades de marketing y la orientación al mercado de empresas argentinas del sector indumentaria. Editorial Académica Española.

Rapaille, C. (2007). El código cultural. Editorial Norma.

Sainz de Vicuña, J. (2016). Plan de internacionalización de la pyme en la práctica. Esic.

Saravia, F., de Juan Vigaray, M. D., \& González, A.M. (2009). Valores y estilos de vida de los consumidores. Pirámide.

Schütz, A. (1999). Estudios sobre Teoría Social. Amorrortu Editores.

Schütz, A. (2012). Estudios sobre Teoría Social. 2da. Ed. Amorrortu Editores.

Sigman, M. (2015). La vida secreta de la mente. Debate. 